\title{
Pengembangan Ekowisata Sungai Berbasis Masyarakat di Desa Pela Kutai Kartanegara, Kalimantan Timur
}

\author{
I Wayan Lanang Nala ${ }^{1}$, Novita Indriani \\ wayanlanang@polnes.ac.id
}

\begin{abstract}
The uniqueness of natural biodiversity in East Kalimantan is a great potential to be developed as tourist attraction, especially related to ecotourism. In the past, pesut was mostly found along the Mahakam River in East Kalimantan, so that they were determined to be the identical fauna of East Kalimantan. However, its currentlypopulation were significanlyt declining so that the Pesut Mahakam is categorized as a protected animal because it is worried that the population will continue to decline. This study aims to identify the potential of tourism resources in Muara Pela area, which is one of roaming and feeding area of Pesut Mahakam and also other natural and cultural potentials that can be holistically developed into community-based ecotourism. This research was conducted using a participatory approach to the community around Muara Pela by assisting the community in the preparation of community-based tourism development programs.
\end{abstract}

Keywords: Community based tourism, Orcaella brevirostris, Ecotourism

\begin{abstract}
Abstrak
Keunikan biodiversitas alam yang dimiliki Kalimantan Timur merupakan potensi yang sangat besar untuk menjadi daya tarik wisata terutama terkait dengan ekowisata. Salah satunya adalah adalah pesut. Jaman dahulu Pesut ini banyak ditemui di Sungai Mahakam, Kalimantan Timur yang merupakan Sub populasi dari hewan ini, sehingga ditetapkan menjadi fauna identitas Propinsi Kalimantan Timur. Namun kondisinya saat ini mengalami penurunan populasi yang sangat signifikan sehingga pesut Mahakam dikategorikan sebagai satwa yang dilindungi karena dikhawatirkan populasinya akan terus mengalami penurunan. Penelitian ini bertujuan untuk mengidentifikasi potensi sumber daya pariwisata yang dimiliki oleh kawasan Muara Pela, bukan hanya satwa pesut Mahakam namun juga potensi alam dan budaya lainnya yang secara holistik dapat dikembangkan menjadi kawasan ekowisata berbasis masyarakat. Penelitian ini dilakukan dengan metode pendekatan partisipatif terhadap masyarakat sekitar Muara Pela dengan cara melakukan pendampingan terhadap masyarakat dalam penyusunan program pengembangan pariwisata berbasis masyarakat.
\end{abstract}

Kata Kunci: Ekowisata sungai, Pesut mahakam, Desa wisata

1 Politeknik Negeri Samarinda 


\section{Pendahuluan}

Kalimantan Timur secara umum memiliki citra sebagai daerah yang kaya dengan potensi ekowisata. Hal ini memang ditunjang dengan kekayaan alam yang tidak hanya berupa keanekaragaman biodiversitas hutan, namun juga terdapat potensi Sungai Mahakam yang membentang melalui Kabupaten Mahakam Ulu, Kutai Barat, Kutai Kartanegara dan Samarinda menuju ke pesisir Muara Jawa. Kekayaan alam yang sangat unik yang terdapat di perairan Sungai Mahakam adalah ikan pesut. Pesut merupakan hewan mamalia yang hidup di air dan tergolong mamalia unik. Berbeda dengan lumba-lumba dan ikan paus, pesut atau nama latinnya Orcaella brevirostris ini hidup di air tawar yang terdapat di sungai-sungai dan danau yang terdapat di daerah tropis dan subtropis. Jaman dahulu Pesut ini banyak ditemui di Sungai Mahakam, Kalimantan Timur yang merupakan Sub populasi dari hewan ini, sehingga ditetapkan menjadi fauna identitas Propinsi Kalimantan Timur (getborneo.com).

Hasil penelitian Dharmadi, et.al (2009) menunjukkan bahwa distribusi pesut Mahakam (Orcaella brevirostris) terkonsentrasi di Sungai Muara Pela yang berhubungan dengan perairan Danau Semayang, Melintang dan Muara Kaman, dengan populasi berkisar 10 - 15 ekor. Di samping itu, kelompok pesut juga terdapat di perairan Muara Pahu. Distribusi pesut berhubungan dengan ketersediaan ikthiofauna sebagai pakan utama. Daerah Muara Kaman dan Danau Semayang merupakan habitat pesut untuk mencari makan, sedangkan Muara Pela merupakan daerah bermain. Dilihat dari kondisi tersebut, pesut Mahakam dikategorikan sebagai satwa yang dilindungi melalui Surat keputusan Menteri No.35/Kpts/Um/1975 karena dikhawatirkan populasinya akan terus mengalami penurunan.

Sebagai salah satu cara untuk melakukan konservasi terhadap keberadaan pesut Mahakam adalah melalui upaya pengembangan ekowisata sungai di kawasan yang menjadi tempat habitat pesut untuk mencari makan (feeding area) ataupun melakukan kegiatan bermain (roaming area).

Berdasarkan sumber dari RIPPDA Kukar (2016), Desa Pela yang berlokasi di kecamatan Kota Bangun Kabupaten Kutai Kartanegara merupakan salah satu lokus dimana kemunculan ikan pesut dapat diamati. Untuk merespon potensi daya tarik ekowisata yang sangat besar ini, Pemerintah Kabupaten Kutai Kartanegara melalui Kebijakan Pariwisata Kabupaten Kutai Kartanegara menempatkan Ekowisata Sungai sebagai salah satu tema primer pembangunan Kawasan Strategis Pariwisata di kawasan Kecamatan Kota Bangun. Kawasan Kota Bangun ini adalah kawasan yang dilintasi Sungai Mahakam yang memiliki potensi besar untuk dikembangkan menjadi Daya Tarik Ekowisata, selain karena panorama alam serta biodiversitas sungai yang unik juga cara hidup masyarakat yang terbentuk sebagai wujud interaksi alam dengan manusianya.

\section{Tantangan}

untuk pengembangan daya tarik wisata di kawasan ini adalah besarnya potensi wisata yang dimiliki serta dapat dikembangkan namun keterbatasan kemampuan masyarakat dalam perencanaan dan pengembangan sehingga dapat memberikan manfaat 
yang besar kepada masyarakat. Pendekatan pemberdayaan masyarakat (community base development) melalui kegiatan pelatihan bertujuan untuk meningkatkan kapasitas masyarakat agar secara mandiri mampu menemukenali, mengidentifikasi masalah, potensi dan kebutuhan wisata, untuk perencanaan dan pengembangan daerah tujuan wisata, serta melakukan kajian analisis dampak sosial, ekonomi dan lingkungan dari pengembangan daerah wisata, dan marketing untuk mempromosikan daerah wisata guna menarik wisatawan.

Komitmen seluruh stakeholder desa (Kelompok Sadar Wisata, Aparat Desa) di desa Pela untuk mengembangkan desa wisata yang ramah lingkungan merupakan modal sosial yang sangat kuat untuk pengembangan desa wisata yang mandiri dan berkelanjutan.

\section{Tipe Artikel}

Artikel merupakan artikel asli hasil penelitian yang dilakukan atas potensi Desa Wisata Pela di Kabupaten Kutai Kartanegara. Adapun permasalahan dan tujuan penelitian tersebut adalah sebagai berikut.

1. Potensi Pariwisata dapat menjadi alternatif sumber pendapatan bagi masyarakat selain dari sektor perikanan tangkap, namun belum dikembangkan secara optimal.

2. Pengembangan pariwisata berbasis masyarakat di Kota Bangun khususnya di Desa Pela dapat menjadi sarana bagi pelestarian sumber daya ekowisata sungai yang terancam keberadaannya.
3. Potensi pariwisata yang sangat unik dimiliki kawasan Desa Pela Kota Bangun belum mampu bersaing dengan daerah lain.

4. Masyarakat belum memiliki pengetahuan yang proporsional tentang kaidah pengembangan pariwisata sehingga dapat mewujudkan kesejahteraan mereka disamping tetap mampu menjaga kelestarian sumber daya pariwisatanya

Sedangkan luaran yang diharapkan dari penelitian ini adalah tersusunnya program pengembangan ekowisata sungai berbasis masyarakat yang mandiri berkelanjutan dan ramah lingkungan.

\section{Metode}

Metode dalam penelitian ini adalah melakukan pemetaan potensi daya tarik wisata dengan mengkaji masalah, kebutuhan, dan hambatan dalam pengembangan pariwisata melalui metode focus group discussion dengan masyarakat setempat. Data yang akan dikumpulkan berupa rincian potensi yang dimiliki dalam rangka penyusunan program pengembangan daya tarik wisata. Selanjutnya diskusi dengan masyarakat juga dilakukan dalam menentukan variabel-variabel utama yang berperan dalam penyusunan kebijakan pengembangan ekowisata sungai di Desa Pela Kota Bangun. Selanjutnya akan dilakukan pendampingan dalam menentukan penetapan program pengembangan ekowisata melalui pelatihan, kosultasi, dan diskusi.

Langkah operasional dalam menentukan pengembangan ekowisata adalah sebagai berikut:

1. Pembentukan tim perencanaan dan pengembangan desa wisata. Dari hasil pelatihan akan dibentuk tim 
atau gugus tugas untuk melakukan pemetaan dan identifikasi masalah, potensi dan kebutuhan wisata.

2. Identifikasi dan pemetaan masalah, potensi, dan kebutuhan serta hambatan untuk pengembangan desa wisata. Tim perencanaan dan pengembangan desa wisata melakukan proses pemetaan, identifikasi masalah, potensi, dan kebutuhan wisata untuk pengembangan menjadi desa wisata.

3. Penyusunan program dan kegiatan pengembangan desa wisata. Hasil pemetaan dan identifikasi masalah, potensi, kebutuhan dan hambatan wisata.

4. Prioritasi program dan kegiatan pengembangan desa wisata. Prioritasi program dan kegiatan yang telah dirumuskan. Prioritasi dilakukan dengan metode pembobotan terhadap manfaat, dampak dan kemampuan untuk pengembangan desa wisata serta melakukan sikronisasi dengan perencanaan jangka menengah desa (PJM Desa) sehingga segala bentuk kegiatan pembangunan desa wisata akan didukung oleh APBDesa.

\section{Hasil dan Pembahasan}

Desa Pela merupakan salah satu desa yang berlokasi di Kecamatan Kota Bangun, Kabupaten Kutai Kartanegara dengan letak geografis pada 116, 57 BT dan 0,22 LS dengan luas wilayah $27 \mathrm{~km}^{2}$ atau sebesar 3.01 $\%$ luas kecamatan Kota Bangun. Jarak kota kecamatan ke desa Pela sepanjang $10 \mathrm{~km}$ ditempuh dengan menggunakan sarana transportasi darat dan transportasi sungai. Penduduk desa Pela berdasarkan laporan pada sistem informasi desa dan kelurahan direktorat jenderal bina pemerintahan desa Kemendagri tahun
2019 adalah 544 jiwa dengan penduduk laki-laki sebanyak 288 jiwa dan perempuan sebanyak 256 jiwa. Jumlah kepala keluarga yang mendiami desa Pela berjumlah 153 KK.

Kecamatan Kota Bangun dalam Angka (2019) menunjukkan Desa Pela merupakan sebuah desa yang terletak di pinggir sungai Pela dengan panjang seluruhnya $20 \mathrm{~km}$. Sungai Pela merupakan sungai yang menghubungkan danau semayang dengan Sungai Mahakam memiliki kedalaman 6 meter dan lebar sungai 100 meter. Desa Pela sendiri merupakan sebuah desa yang seluruh wilayahnya merupakan wilayah perairan sehingga berpengaruh pada sumber mata pencaharian masyarakat yang didominasi oleh kehidupan nelayan. Mata pencaharian utama masyarakat desa Pela adalah sebagai nelayan sungai. Adapun kegiatan nelayan sebagian dilakukan dengan cara tangkap.

Desa Pela ditetapkan sebagai desa wisata dengan daya tarik wisata danau dengan ekosistem pesut melalui keputusan Bupati Kutai Kartanegara nomor 250/SKBUP/HK/2019. Penetapan desa Pela sebagai desa wisata ini didasari atas pertimbangan perkembangan aktivitas pariwisata di kawasan ini serta berdasarkan rencana induk pembangunan pariwisata daerah terhadap upaya strategis untuk peningkatan potensi dan kapasitas sumber daya lokal dalam meningkatkan daya tarik dan kunjungan wisatawan serta diperlukannya peran serta masyarakat dalam perencanaan dan pengelolaan pariwisata di lingkungannya. 


\section{Daya Tarik Desa Pela sebagai Desa Wisata Berbasis Wisata Sungai dan Danau dengan Ekosistem Pesut}

Desa Pela ditetapkan sebagai desa wisata dengan berbasis wisata danau dan sungai dengan ekosistem pesut. Wisata danau yang dimaksudkan adalah karena posisi geografis desa Pela yang berada di sungai Pela berdekatan dengan danau semayang yang merupakan daerah perlintasan pesut. Selain itu, aktifitas masyarakat yang didominasi oleh perikanan tangkap, sangat bergantung kepada keberadaan sungai Pela dan danau Semayang.

Berbagai daya tarik yang menjadi potensi wisata di desa Pela diantaranya adalah, ekosistem pesut, pesona alam danau Semayang, kehidupan nelayan tangkap serta kebudayaan daerah setempat.

Pesut merupakan hewan mamalia yang hidup di air dan tergolong mamalia unik. Berbeda dengan lumba-lumba dan ikan paus, pesut atau nama latinnya Orcaella brevirostris ini hidup di air tawar yang terdapat di sungai-sungai dan danau yang terdapat di daerah tropis dan subtropis.Jaman dahulu Pesut ini banyak ditemui di Sungai Mahakam, Kalimantan Timur yang merupakan Sub populasi dari hewan ini, sehingga ditetapkan menjadi fauna identitas Propinsi Kalimantan Timur. Namun kondisinya saat ini mengalami penurunan populasi yang sangat signifikan sehingga pesut Mahakam dikategorikan sebagai satwa yang dilindungi karena dikhawatirkan populasinya akan terus mengalami penurunan.

Menurut Kreb (2004), Noor (2016) penyebaran populasi satwa liar ini tidak merata di seluruh bagian sungai, anak-anak sungai serta danaudanau Mahakam. Mereka umumnya terkonsentrasi di bagian tengah Sungai Mahakam. Kawasan yang menjadi penyebaran populasi pesut pada masa lalu mencakup alur Sungai Mahakam antara Loa Kulu di bagian hilir yang berjarak sekitar 90 kilometer dari muara dan Burit Halau di Long Bagun (bagian hulu) berjarak sekitar 600 kilometer dari muara, danau-danau yang tersebar di sungai Mahakam seperti Danau Semayang, Danau Melintang dan Danau Jempang, dan anak-anak sungai Mahakam seperti Sungai Kedang Rantau, Sungai Kedang Kepala, Sungai Belayan, Sungai Kedang Pahu dan Sungai Ratah hingga sejauh 100 km ke arah hulunya.

Danau Semayang terletak sekitar satujam perjalanan dari Kecamatan Kota Bangun jika menggunakan Long Boat. Di danau ini wisatawan dapat menikmati pemandangan hamparan air danau yang tenang tanpa batas terutama pada saat matahari terbit dan matahari terbenam. Lokasi yang saat ini menjadi daya tarik yang cukup kuat bagi wisatawan lokal adalah pesona Danau Semayang dengan latar belakang matahari terbenam pada sore hari. Lokasi ini oleh masyarakat Desa Pela disebut sebagai Tanjung Tamannoh.

Perekonomian masyarakat di Desa Pela sangat tergantung pada ekosistem Danau Semayang dan Sungai Pela yang menghubungkan Danau Semayang dengan Sungai Mahakam. Lokasi ini merupakan kawasan dengan sumberdaya alam yang memiliki keanekaragam hayati perikanan dengan nilai ekonomis tinggi. Kawasan danau ini memiliki eksistensi yang tinggi terhadap aktivitas perekonomian masyarakat yang bermukim di sekitar kawasan. Sumberdaya perikanan yang terdapat di danau ini telah lama dimanfaatkan 
dan dikelola oleh masyarakat lokal sebagai mata pencaharian utamanya, dalam bentuk berbagai usaha perikanan seperti penangkapan dan budi daya ikan dalam karamba. Nelayan Desa Pela merupakan satu diantara kelompok masyarakat yang memanfaatkan kawasan perairan ini sebagai ladang mata pencaharian mereka. Kehidupan nelayan tangkap sendiri merupakan daya tarik yang kuat yang dapat dijadikan sebagai bagian dari produk wisata di Desa Pela.

\section{Pengembangan Desa Wisata Pela}

Sebagaimana $\begin{array}{r}\text { halnya } \\ \text { perencanaan } \\ \text { pariwisata, pengembangan Desanan }\end{array}$
Wisata Pela juga perlu
memperhatikan
pengembangan yang mencakup
diantaranya pembangunan Desa Pela
sebagai Destinasi, pembangunan
kelembagaan desa r wisata,
pembangunan usaha pariwisata
masyarakat, pembangunan
pemasaran desa wisata.

Pembangunan destinasi akan meliputi pembangunan fisik daya tarik wisata, peningkatan penyediaan fasilitas umum dasar, peningkatan kemudahan dan ketersediaan informasi, pembangunan infrastruktur pendukung, perbaikan dan peningkatan aksesibilitas di dalam Desa Pela, peningkatan aksesibilitas ke destinasi lain dalam area kawasan yang lebih luas, peningkatan peran serta masyarakat dalam proses pembangunan Desa Wisata Pela.

Dalam hal pembangunan fisik daya tarik, Desa Pela telah memulai dengan membangun papan nama untuk memberikan tanda sekaligus sebagai pembangunan citra pariwisata yang ingin dibangun oleh Desa Wisata. Selain itu, fasilitas lainnya yang saat ini sedang dibangun melalui bantuan pendanaan dari alokasi dana desa adalah pembuatan jembatan/jalur yang menghubungkan kawasan pemukiman menuju Tanjung Tamannoh agar dapat ditempuh dengan berjalan kaki. Fasilitas dan daya tarik fisik lainnya adalah pembuatan Gazebo yang diperuntukkan bagi pusat informasi pariwisata dan sekaligus akan dimanfaatkan sebagai pusat oleh-oleh khas Desa Pela.

Infrastruktur dasar seperti ketersediaan pasokan listrik dan jaringan internet sudah terlayani, sedangkan air bersih saat ini telah menjadi program Pemerintah Daerah Kutai Kartanegara agar dapat menjangkau Desa Pela. Dukungan pemerintah daerah baik Kabupaten Kutai Kartanegara maupun Pemerintah Provinsi Kalimantan Timur melalui Dinas Pariwisata adalah faktor yang memperkuat keyakinan masyarakat untuk dapat mengembangkan kepariwisataan di Desa Pela.

Dalam hal pembangunan kelembagaan, Desa Pela sendiri telah ditetapkan sebagai sebagai desa wisata dengan daya tarik wisata danau dengan ekosistem pesut melalui keputusan Bupati Kutai Kartanegara nomor 250/SKBUP/HK/2019. Sebelum penetapan Desa Pela sebagai desa wisata, telah ditetapkan juga kelompok sadar wisata Desa Pela dengan nama Pokdarwis Bekayuh Baumbai Babudaya. Pokdarwis inilah yang ditunjuk oleh pemerintah Pemerintah Kabupaten Kutai Kartanegara melalui Dinas Pariwisata untuk melakukan pengelolaan terhadap potensi pariwisata di Desa Pela dengan misi utama melakukan kegiatan sadar wisata untuk masyarakat. 
Kedua penetapan kelembagaan tersebut masih dalam tahap koordinasi sehingga penetapan kelembagaan lain terutama yang berhubungan dengan pendanaan masih belum terkelola dengan baik, dalam artian Pokdarwis saat ini masih berjalan sesuai dengan arahan Dinas Pariwisata Kabupaten Kutai Kartanegara dan belum memiliki pendanaan mandiri.

Selanjutnya

adalah

pembangunan usaha pariwisata masyarakat. Dalam hal pembangunan usaha masyarakat saat ini telah dirangsang kepada warga desa yang menginginkan untuk berpartisipasi dalam usaha pariwisata yakni penyediaan Homestay. Saat ini telah ada 5 (lima) warga yang menyatakan bersedia menyediakan rumahnya sebagai homestay namun hanya 3 (tiga) rumah yang menyatakan siap untuk menerima tamu. Selain itu, melalui pokdarwis dan pendampingan dari dinas perindustrian juga telah memberikan pelatihan kepada masyarakat untuk menginisiasi usaha kerajinan berbasis bahan baku lokal, seperti pengolahan ikan kering, kerajinan kerupuk ikan dan kerajinan sandal berbahan eceng gondok.

Produk atau pengalaman wisatawan merupakan pondasi bagi kesuksesan usaha Desa Wisata. Tanpa tersedianya produk yang bisa dipasarkan, maka tidak ada alasan bagi wisatawan untuk datang ke desa tersebut dan usaha Desa Wisata tidak akan berjalan dengan baik. Karenanya, aspek-aspek identifikasi, pengembangan dan implementasi dari produk wisata, merupakan hal-hal yang sangat penting untuk kesuksesan usaha Desa Wisata.

Produk wisata bagi desa wisata adalah pengalaman menyeluruh interaksi wisatawan dengan masyarakat lokal, yang mencakup layanan transportasi, akomodasi, makanan dan minuman dan kegiatan yang dapat dilakukan di Desa Pela. Saat ini Desa Pela sedang merancang paket wisata melalui pendampingan oleh perguruan tinggi. Adapun pendampingan dilakukan dengan metode pelatihan penyusunan paket kunjungan wisata Desa Pela. Dalam pelatihan tersebut, disepakati bahwa untuk produk wisata Desa Pela, atraksi utamanya adalah melihat ikan pesut. Namun daya tarik lainnya dapat ditambahkan selama wisatawan berada di Desa Pela. Karena pesut biasanya muncul pada sore atau pagi hari, maka untuk mendapat pengalaman menyeluruh produk wisata Desa Pela, wisatawan dianjurkan untuk bermalam.

Jika dilihat dari karakteristik produk yang tersedia di Desa Pela saat ini, target pasar yang cocok untuk pasar sasaran produk wisata Desa Pela adalah sekolah-sekolah menengah di perkotaan seperti Tenggarong, Samarinda, Balikpapan dan Bontang. Segmen pasar ini menjadi pasar utama karena siswa perkotaan biasanya memiliki kecenderungan untuk ingin tahu kehidupan pedesaan sebagai pengalaman langsung berinteraksi dengan alam. Segmen pasar lainnya adalah segmen yang bersifat tambahan bagi promosi produk wisata Desa Pela yaitu segmen wisatawan minat khusus yang sangat tertarik dengan keberadaan pesut. Untuk segmen seperti ini, Pokdarwis dapat bekerjasama dengan pihak swasta atau Biro Perjalanan yang memiliki target pasar wisatawan mancanegara minat khusus.

Untuk mempublikasikan produk wisatanya, pokdarwis Desa Pela lebih banyak menggunakan media sosial 
karena relatif murah. Selain itu, kekuatan Pokdarwis adalah jaringan kerja sama dengan lembaga swadaya masyarakat atau komunitaskomunitas setempat yang membantu pemerintah daerah untuk promosi pariwisata. Selain itu, karena keunikan daya tarik yang cukup besar, beberapa media elektronik nasional juga melakukan liputan untuk ditayangkan di televisi dengan jangkauan nasional. Kesempatan seperti ini kemudian "diviralkan" untuk mendapat perhatian publik sebagai sarana promosi bagi produk wisata Desa Pela. Namun demikian cara promosi yang lebih menyasar target pasar juga tengah disiapkan dalam rangka mempublikasikan produk wisata kepada sekolahsekolah di perkotaan seperti Tenggarong, Samarinda, Bontang dan Balikpapan mengingat produk wisata perdesaan cocok dan seringkali diminati oleh siswa di perkotaan.

\section{Kesimpulan}

Pencanangan Desa Wisata untuk Desa Pela didasarkan pada besarnya potensi wisata yang dimiliki oleh kawasan Desa Pela terkait dengan interaksi mereka terhadap alam sekitar mereka. Pengembangan pariwisata merupakan salah satu cara untuk membangun masyarakat dalam rangka mewujudkan kesejahteraan masyarakat serta melakukan pelestarian terhadap lingkungan. Sejalan dengan pengembangan pariwisata di Desa Pela telah memberikan penyadaran kepada masyarakat tentang pelestarian lingkungan salah satunya melalui cara tangkap yang lebih ramah terhadap pesut. Pengembangan ekowisata dengan mengedepankan prinsip "semakin dilestarikan semakin menyejahterakan" merupakan salah satu pilihan yang paling tepat dilakukan di Desa Wisata Pela.

\section{Saran}

Adapun saran untuk pengembangan Desa Wisata Pela adalah sebagai berikut:

1. Pokdarwis hendaknya lebih dapat berkoordinasi dengan lebih baik dengan Bumdes setempat dalam rangka memperkuat pendanaan dan sistem keuangan Desa Wisata.

2. Pemerintah Daerah perlu segera menyediakan pelayanan air bersih dalam rangka meningkatkan kualitas layanan homestay setempat.

3. Peningkatan kualitas produk wisata untuk dikemas menjadi paket wisata perlu senantiasa dilakukan untuk dapat ditawarkan kepada wisatawan.

4. Penggunaan saluran pemasaran seperti promosi produk wisata/paket wisata kepada target pasar siswa sekolah secara langsung perlu digencarkan untuk menjaring semakin banyak segmen pengunjung di Desa Pela.

\section{Daftar Pustaka}

ASEAN Community Based Tourism Standard. (2016). ASEAN Secretariat, Jakarta.

$\begin{array}{lrr}\text { Budiono dkk } & (2007) \\ \text { Keanekaragaman } & \text { Hayati di } \\ \text { Danau dan Lahan } & \text { Basah pada } \\ \text { Daerah Mahakam } & \text { Tengah, } \\ \text { Kalimantan Timur } & \text { 2005-2007. } \\ \text { Mahakam Bird } & \text { Assesment } \\ \text { Suvey, YK-RASI. } & \end{array}$


Kruger, M., \&Saayman, M. (2009). Factor analysis, Kruger National Park, South Africa, Travel motives and Tsitsikamma National Park. South African Journal of Wildlife Research,Volume 40, Issue 1, Apr 2010, p. 93 - 102.

Luo, Y., \& Deng, J. (2008). The New Environmental Paradigm and Nature-Based Tourism Motivation. Journal of Travel Research, 46(4), 392-402. https://doi.org/10.1177/00472875 07308331 .

Muallidin, I. (2007). Model Pengembangan Pariwisata Berbasis Masyarakat. Jurnal Penelitian Bappeda Kota Yogyakarta. Vol. 02. 05-14

Noor, Ivan Y. (2016). Pesut Mahakam. Profil, Peluang Kepunahan dan Upaya Konservasinya. Pusat Pengendalian Pembangunan Ekoregion Kalimantan,
Kementrian Lingkungan Hidup dan Kehutanan.

Peraturan Daerah (Perda) Kabupaten Kutai Kartanegara No. 19 Tahun 2016 tentang Rencana Induk Pembangunan Pariwisata Kutai Kartanegara. JDIH BPK RI. https://peraturan.bpk.go.id/Home /Details/72946/perda-kab-kutaikertanegara-no-19-tahun-2016.

Revalda A. J. B. Salakory. (2016). Pengembangan Ekowisata Berbasis Masyarakat di Kepulauan Banda, Kabupaten Maluku Tengah. Jurnal Ilmu Pertanian "AGRIKA" , Vol. 10, No. 1.

Salim, H.L., \& Purbani, D. (2015. Pengembangan Pariwisata Bahari Berbasis Masyarakat di Pulau Kaledupa, Kabupaten Wakatobi, Provinsi Sulawesi Tenggara. Jurnal Manusia dan Lingkungan. Vol. 22, No. 3, November 2015: 380-387. 
